\title{
Different Forms of Synaptic Plasticity in Somatosensory and Motor Areas of the Neocortex
}

\author{
Manuel A. Castro-Alamancos, John P. Donoghue, and Barry W. Connors \\ Department of Neuroscience, Brown University, Providence, Rhode Island 02912
}

We have studied vertical synaptic pathways in two cytoarchitectonically distinct areas of rat neocortex-the granular primary somatosensory (SI) area and the agranular primary motor (MI) area-and tested their propensity to generate long-term potentiation (LTP), long-term depression (LTD), and related forms of synaptic plasticity. Extracellular and intracellular responses were recorded in layer II/III of slices in vitro while stimulating in middle cortical layers (in or around layer IV). Under control conditions, $5 \mathrm{~Hz}$ theta-burst stimulation produced LTP in the granular area, but not in the agranular area. Agranular cortex did generate shortterm potentiation that decayed within 20 min. Varying the inter-burst frequency from $2 \mathrm{~Hz}$ to $10 \mathrm{~Hz}$ reliably yielded LTP of 21-34\% above control levels in granular cortex, but no lasting changes were induced in agranular cortex. However, the agranular cortex was capable of generating LTP

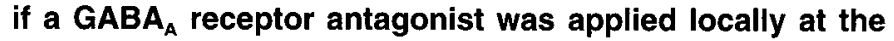
recording site during the induction phase. In contrast to LTP, an identical form of homosynaptic LTD could be induced in both granular and agranular areas by applying low frequency stimulation (1 Hz for $15 \mathrm{~min}$ ) to the middle layers. Under control conditions, both LTP and LTD were synapse-specific; theta-burst or low-frequency stimulation in the vertical pathway did not induce changes in responses to stimulation of a layer II/III horizontal pathway.

Application of the NMDA receptor antagonist D-2-amino5-phosphonovaleric acid (AP5) blocked the induction of both LTP and LTD in granular and agranular cortex. In the presence of AP5, low-frequency conditioning stimuli yielded a short-term depression in both areas that decayed within 10-15 $\mathrm{min}$. Nifedipine, which blocks L-type, voltagesensitive calcium channels, slightly depressed the magnitudes of LTP and LTD but did not abolish them.

Synaptic responses evoked during theta-burst stimulation were strikingly different in granular and agranular areas. Responses in granular cortex were progressively facilitated during each sequence of 10 theta-bursts, and from sequence-to-sequence; in contrast, responses in agranular cortex were stable during an entire theta-burst tetanus.

The results suggest that vertical pathways in primary so-

\footnotetext{
Received Jan. 3, 1995; revised Feb. 21, 1995; accepted Mar. 10, 1995.

We thank Mark Bear and Alfredo Kirkwood for stimulating discussions. This study was supported by fellowships to M.A.C. from the Ministry of Science and Education of Spain and the NIMH (MH19118), a grant to J.P.D. from the NIH (NS22517), and grants to B.W.C. from the NIH (NS25983) and the ONR (N00014-90-J-1701).

Correspondence should be addressed to Barry W. Connors, Ph.D., Box GM, Department of Neuroscience, Brown University, Providence, RI 02912.

Copyright $\odot 1995$ Society for Neuroscience 0270-6474/95/155324-10\$05.00/0
}

matosensory cortex and primary motor cortex express several forms of synaptic plasticity. They were equally capable of generating LTD, but the pathways in somatosensory cortex much more reliably generated LTP, unless inhibition was reduced. LTP may be more easily produced in sensory cortex because of the pronounced synaptic facilitation that occurs there during repetitive stimulation of the induction phase. In addition, both cortical areas generated short-term potentiation and short-term depression under certain conditions. Thus, the ability to generate short- and long-term forms of synaptic plasticity may vary in similar synaptic pathways of different neocortical areas.

[Key words: long-term potentiation, short-term potentiation, facilitation, long-term depression, NMDA receptors, nifedipine, sensorimotor cortex]

Many forms of synaptic plasticity have been observed in the cerebral cortex. The phenomena and mechanisms of plasticity have been intensively studied in the hippocampus (Madison et al., 1991; Bliss and Collingridge, 1993; Malenka and Nicoll, 1993; Bear and Malenka, 1994; Debanne and Thompson, 1994), and they include paired-pulse facilitation (lasting less than one sec), short-term potentiation (STP, 5-20 min), long-term potentiation (LTP, hours or more) and long-term depression (LTD, hours). Some of these phenomena have also been observed in neocortex; for example, both the CA1 area of hippocampus and the primary visual neocortex can generate long-term potentiation (LTP) or long-term depression (LTD) in response to similar induction stimuli (Kirkwood et al., 1993). However, the growing literature on neocortical plasticity reports variable, often contradictory results (reviewed by Artola and Singer, 1993; Bear and Kirkwood, 1993). In part this is because studies have employed a wide range of cortical areas, axonal pathways, postsynaptic neurons, developmental ages, species, and experimental conditions. No single study has examined the plasticity of homologous pathways in two neocortical areas under similar conditions. Studies of hippocampus suggest that region-specific plasticity may be common: LTP in the Schaeffer collateral-CA1 pathway has properties and mechanisms entirely distinct from LTP of the mossy fiber-CA3 pathway (Williams and Johnston, 1989; Zalutsky and Nicoll, 1993).

Neocortical LTP and LTD have been studied most frequently in the primary visual area (Lee, 1982; Artola and Singer, 1987; Aroniadou and Teyler, 1991; Komatsu et al., 1991; Bear et al., 1992; Hirsch and Gilbert, 1993; Kirkwood and Bear, 1994a,b). LTP has also heen observed in the primary somatosensory cortex (Lee et al., 1991), the primary motor cortex (Baranyi and Szente, 1987; Baranyi et al., 1991; Iriki et al., 1991; Hess and Donoghue, 1994), and undefined frontal regions of rat neocortex 
(Bindman et al., 1988; Sutor and Hablitz, 1989); however, LTD has not yet been reported for any of these areas. Studies of neocortical LTP have used a wide variety of stimulus protocols, pathways and conditions, sometimes including a reduction of $\mathrm{GABA}_{\mathrm{A}}$ receptor-mediated inhibition. Recently Kirkwood and Bear (1994a,b) introduced reliable, drug-free induction protocols for homosynaptic LTP an LTD in rat visual cortex. In each case, conditioning stimuli are applied to layer IV while recording in layer III. LTP is induced by several sets of theta-burst stimulation; LTD is induced by relatively low frequency $(1-2 \mathrm{~Hz})$ stimulation for $15 \mathrm{~min}$. These forms of LTP and LTD closely resemble those of the Schaffer collateral-CA1 pathway in hippocampus. Both are dependent upon activation of NMDA receptors, and presumably both require an increase of internal postsynaptic $\left[\mathrm{Ca}^{2+}\right]$ (Bear and Malenka, 1994).

In the present study we compared activity-dependent synaptic modification in vertical pathways of two adjacent, but structurally and functionally distinct, regions of rat neocortex: the granular primary somatosensory area, and the agranular primary motor area. Our investigation had several aims: (1) to test the generality of the LTP and LTD induction protocols recently described for visual cortex; (2) to compare directly, under very similar conditions, the synaptic plasticity of two neocortical areas; (3) to explore the range of plasticity, both short- and longterm, that can be induced in neocortex; (4) to begin probing the induction mechanisms of synaptic plasticity in neocortex.

Primary motor and somatosensory cortices of the rodent are well suited to these studies. The areas are adjacent, and so can be easily studied in vitro in the same slice at the same time, yet they are distinct in both lamination and in function. Synaptic modifications demonstrable in vitro may be involved in cortical functions and reorganization in vivo, and both somatosensory and motor areas of the adult rat can reorganize in response to central or peripheral manipulations (Donoghue et al., 1990; Castro-Alamancos et al., 1992; Recanzone et al., 1992; Diamond et al., 1993). Our results show that while motor and somatosensory cortex can express a variety of types of synaptic plasticity, they are not identical in their capabilities. The vertical pathways of somatosensory cortex (but not motor cortex) can generate LTP under control conditions, perhaps because synaptic responses in the former (but not the latter) also express a short-term facilitation during tetanic stimulation.

\section{Materials and Methods}

Slices were prepared from the parietofrontal cortex of mature SpragueDawley rats $(>150 \mathrm{gm})$. Animals were anesthetized with intraperitoneal injection of pentobarbital and decapitated immediately after the disappearance of tail pinch reflexes. The brain was rapidly removed and immersed in ice-cold dissection buffer containing (in $\mathrm{mM}$ ) $\mathrm{NaCl}, 124$; $\mathrm{KCl}, 5 ; \mathrm{NaH}_{2} \mathrm{PO}_{4}, 1.25 ; \mathrm{MgSO}_{4}, 1 ; \mathrm{CaCl}_{2}, 2 ; \mathrm{NaHCO}_{3}, 26$; dextrose, 10. A block of frontoparietal cortex was removed and sectioned in the coronal plane into $400 \mu \mathrm{m}$ thick slices using a Microslicer (DTK). The slices were collected and transferred to a slice chamber, where they were maintained at the liquid-gas interface in an atmosphere of humidified $95 \% \mathrm{O}_{2}$ and $5 \% \mathrm{CO}_{2}$, and superfused with the previously described buffer at $35.5^{\circ} \mathrm{C}$ at a rate of $1 \mathrm{ml} / \mathrm{min}$. Slices were left undisturbed for at least $1 \mathrm{hr}$ before starting any recording or stimulation.

When bicuculline methiodide (BMI) was used to suppress $\mathrm{GABA}_{\mathrm{A}}$ receptors, it was included in the recording pipette $(5 \mathrm{mM}$ dissolved in $0.25 \mathrm{M} \mathrm{NaCl}$ ). To block NMDA receptors, D-2-amino-5-phosphonovaleric acid (AP5) was included in the recording pipette $(10 \mathrm{mM})$ with $0.25 \mathrm{M} \mathrm{NaCl}$, or dissolved in the bathing medium $(100 \mu \mathrm{M})$. Nifedipine was used to suppress L-type calcium channels, and it was first dissolved in DMSO at $1 \mathrm{M}$, then diluted in $0.25 \mathrm{M} \mathrm{NaCl}$ to a final concentration of $10 \mathrm{mM}$, which was then included in the recording pipette. To block non-NMDA receptors, 6,7-dintroquinoxaline-2,3-dione (DNQX) was in-

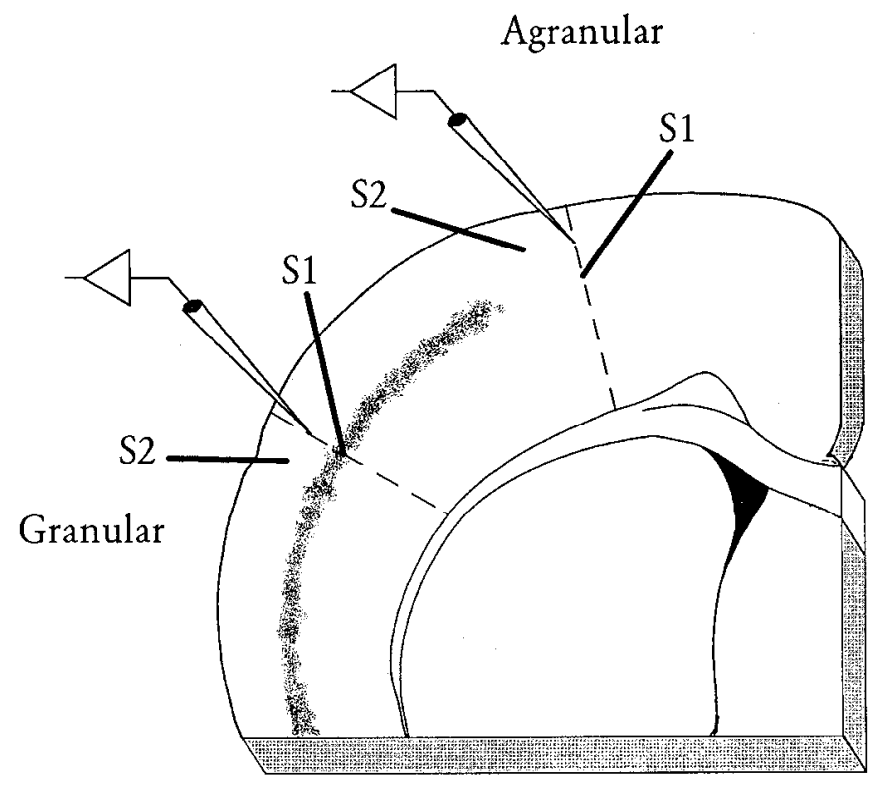

Figure 1. Schematic diagram of neocortical slice preparation. The granular area is represented by stippling in layer IV; the agranular area lacks a clear layer IV. Slices were cut in the coronal plane; medial is to the right, dorsal on top. Recording electrodes were placed in the middle of layer II/III. Stimulating electrodes were placed as shown, so as to activate vertical pathways $(S I)$ or horizontal pathways $(S 2)$ in each area.

cluded in the bathing medium $(20 \mu \mathrm{M}$ or $80 \mu \mathrm{M})$. Pharmacological agents were purchased from Sigma or Research Biochemicals International.

Extracellular recording was performed with glass micropipettes filled with $0.25 \mathrm{M} \mathrm{NaCl}$; their resistances were 1-2 M $\Omega$ Intracellular (conventional sharp-type) recording electrodes were filled with $3 \mathrm{M} \mathrm{K}$-acetate $(80-120 \mathrm{M} \Omega)$, and recordings were made from layer III cells identified physiologically as pyramidal neurons (Connors and Gutnick, 1990). Input resistances were estimated by injecting small $(0.1-0.2 \mathrm{nA})$ hyperpolarizing current steps, measuring the steady-state membrane voltage deflections after carefully balancing the bridge, and calculating from Ohm's law.

Synaptic responses were evoked with $200 \mu$ sec pulses of $10-60 \mu \mathrm{A}$ delivered through a concentric bipolar stimulating electrode. Stimulation was applied to the middle region of the cortex $(700-800 \mu \mathrm{m}$ from the pial surface) at a site that corresponds to layer IV in the granular cortex and to the transition from layer $\mathrm{V}$ to layer III in the agranular cortex (Fig. 1). Baseline (control) responses were obtained at $0.1 \mathrm{~Hz}$ using a stimulation intensity that produced approximately a half-maximal field potential (for extracellular experiments), or two-thirds of the current needed to produce an orthodromic action potential (intracellular experiments). The recording electrode and primary (S1) stimulating electrode were carefully aligned along the vertical axis of the cortex. Layer II/III field potentials evoked by S1 stimulation varied in shape from slice-to-slice, although there was no consistent difference between fields from granular and agranular cortex. Examples from each are shown in Figure 2, $C$ and $D$; these were chosen to illustrate the range of field potentials encountered, and are not meant to imply a consistent difference between granular and agranular cortex. In general, the field potentials contained a short-latency negative component that either merged with (Fig. $2 C$ ) or was distinctly separate from (Fig. $2 D$ ) a longer-latency, larger amplitude second negativity. The first field potential Ilegativity preceded intracellularly recorded EPSPs in layer II/III (compare top and bottom traces in Fig. $2 C, D$ ), and was resistant to the nonNMDA receptor antagonist DNQX, implying that it originated from nonsynaptic sources such as presynaptic fibers or antidromic firing.

A second stimulating electrode (S2) was usually placed $300-500 \mu \mathrm{m}$ lateral to, and at the same subpial depth as, the recording electrode within layer II/III; this activated horizontal fibers, and was used to test the specificity of modifications in the conditioned pathway. The standard induction protocol for LTP was six theta-burst sequences, delivered at one sequence every $10 \mathrm{sec}$. Each theta-burst sequence consisted of 


\section{A}
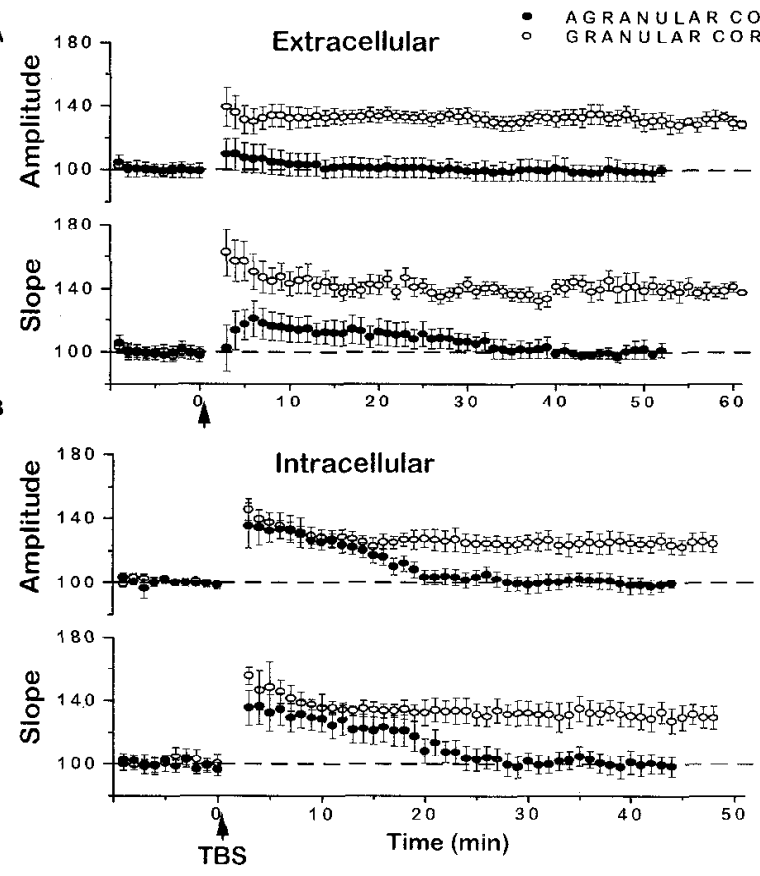

C
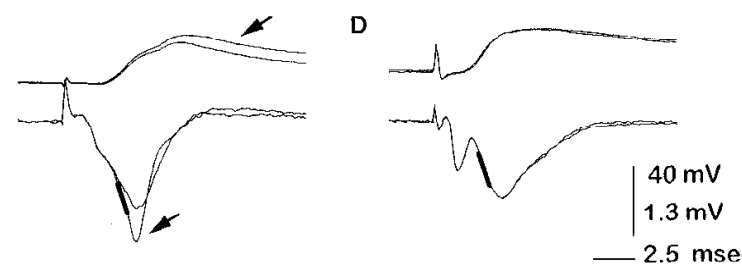

Figure 2. Long-term effects of theta-burst stimulation on synaptic efficacy in granular and agranular areas. $A$, Graphs plot the peak amplitude (top) and maximal slope (bottom) of the extracellular (field potential) response to S1 stimulation in granular (open symbols) and agranular (solid symbols) areas. Data from 10 experiments in each area were pooled. Following $10 \mathrm{~min}$ of baseline recording, theta-burst stimulation (TBS) was applied at the time of the arrow. LTP in the granular area is evident as an increase in both amplitude and slope as long as $60 \mathrm{~min}$ after TBS. The agranular area generated only STP, returning to baseline within about $30 \mathrm{~min}$. Data are expressed here and in all subsequent graphs as mean \pm SEM. $B$, Effects of theta-burst stimulation on EPSPs recorded intracellularly from seven layer II/III pyramidal cells in each cortical area. Protocols were the same as in A. Again, LTP is evident in granular area, but only STP is generated in the agranular area. $C$, Examples of simultaneously recorded intracellular EPSPs (top) and extracellular field potentials (bottom) in the granular cortex immediately before and $30 \mathrm{~min}$ after (arrows) application of theta-burst stimulation. The thick line on the field potential trace illustrates the region from which slope determinations were made. $D$, Example recordings (as in C) from agranular cortex immediately before and $30 \mathrm{~min}$ after thetaburst stimulation. The differences in the waveforms between $C$ and $D$ do not represent consistent differences between areas, but serve to illustrate the range seen in both areas.

10 bursts (one burst -5 pulses at $100 \mathrm{~Hz}$ ) delivered at $5 \mathrm{~Hz}$, unless specified otherwise. Thus, an entire theta-burst induction tetanus had a total of 300 pulses organized into 60 bursts. The standard induction protocol for LTD consisted of 900 continual pulses delivered at $1 \mathrm{~Hz}$.

Synaptic responses were sampled at $10 \mathrm{kHz}$ and stored on a computer using EXPERIMENTER's WORKBENCH (Data Wave Technologies). The maximal rising slope and amplitude of the field potential and of the intracellular postsynaptic potential (EPSP) were calculated as measures of the population and cellular synaptic efficacy, respectively. In the case of the field potential, the slope measurement was made from the rising phase of the second negativity, which coincides with the latency of the rising phase of the EPSPs (see thick lines on traces in Fig. 2C,D). A steady baseline for at least $10 \mathrm{~min}$ was a requirement for any experiment to be initiated. The time scale in all graphs has been adjusted so that zero time corresponds to the beginning of the conditioning stimulation. Data are expressed as a percentage ( \pm SEM) of the mean preconditioning baseline.

\section{Results}

\section{ITP in granular cortex}

Stimulation of layer IV in the granular cortex reliably generated LTP in layer II/III when the theta-burst protocol was applied. The field potential in layer II/III showed an elevated amplitude and slope immediately after the conditioning tetanus, and after $60 \mathrm{~min}$ they were still an average of $130-140 \%$ of control values (Fig. 2A, open symbols). A similar effect was evident in the slope and amplitude of EPSPs recorded intracellularly from pyramidal cells of layer II/III (Fig. 2B, open symbols). Examples of field potentials and intracellular recordings from granular cortex, before and after conditioning, are shown in Figure $2 C$. The resting potentials of 10 intracellularly recorded neurons in layer II/III of granular cortex was $-78 \pm 1 \mathrm{mV}$ (mean $\pm \mathrm{SEM}$ ), and the input resistance was $38 \pm 3 \mathrm{M} \Omega$

In each experiment, test stimuli applied to the horizontal S2 pathway showed no evidence of lasting changes in synaptic efficacy after conditioning stimuli were applied to the $S 1$ pathway (not shown, but similar to Fig. $4 A$, triangles). In some cases there was a transient depression of the $S 2$ response following $S 1$ conditioning, but the $\mathrm{S} 2$ responses returned to baseline levels within about $10 \mathrm{~min}$. Thus, the LTP observed after theta-burst stimulation of vertical pathway was input-specific, and was not a general enhancement of all synapses onto layer II/III cells.

\section{$L T P$ in agranular cortex: requirement for reduced $G A B A_{A}$ receptor-mediated inhibition}

Single stimuli applied near the border of layers IV/III and IV in agranular cortex generated robust field potential and synaptic responses (Fig. $2 D$ ). The resting potentials of 10 intracellularly recorded neurons in agranular cortex was $-77 \pm 1 \mathrm{mV}$ (mean \pm SEM), and the input resistance was $36 \pm 3 \mathrm{M} \Omega$ The thetaburst protocol did not generate LTP as assessed by the amplitude or slope of either the field potentials or intracellularly recorded EPSPs (Fig. $2 A, B$, solid symbols). Instead, conditioning stimulation generated a short-term potentiation (STP) that endured no more than 20-25 min. STP was more evident in intracellular recordings than in field potentials (Fig. $2 A, B$ ). The STP was specific to the conditioned pathway, since it was not obscrved in the control, unconditioned S2 pathway (not shown). Strength of stimulation does not seem to account for the failure to generate LTP; moving the stimulating electrode into layer II/III, to within about $100 \mu \mathrm{m}$ of the recording sites, significantly increased the size of responses to a given stimulus intensity, but did not lead to the generation of LTP.

We were concerned that the agranular cortex might not have generated LTP because the theta-burst conditioning protocol was not tuned to its optimal LTP-induction frequency. However, when the interburst frequency was varied between $2 \mathrm{~Hz}, 5 \mathrm{~Hz}$, and $10 \mathrm{~Hz}$, granular cortex still produced LTP while agranular cortex did not (Fig. 3A). Grouped data show that the granular cortex was sensitive to interburst frequency, with LTP magnitude rising from $21 \%$ to $34 \%$ between $2 \mathrm{~Hz}$ and $10 \mathrm{~Hz}$ (Fig. $3 B$ ). In contrast, agranular cortex did not generate a significant LTP at any frequency tested.

Inhibition mediated by $\mathrm{GABA}_{\mathrm{A}}$ receptors is very powerful in neocortex (Connors et al, 1988), and IPSPs are strongly engaged by the conditioning stimuli normally used to induce LTP. 
A
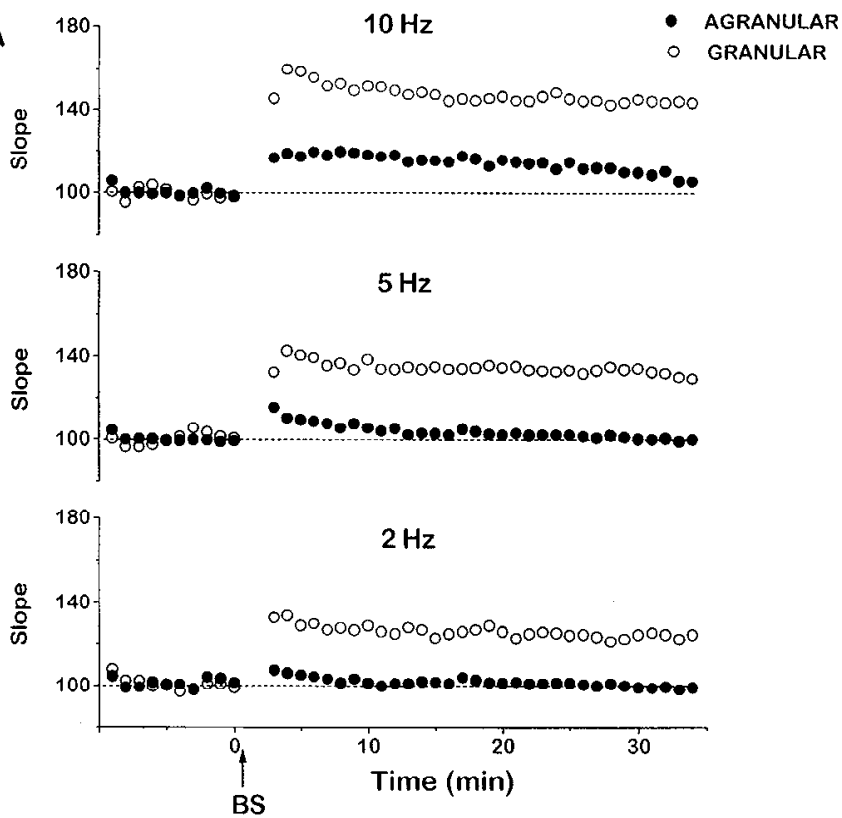

B

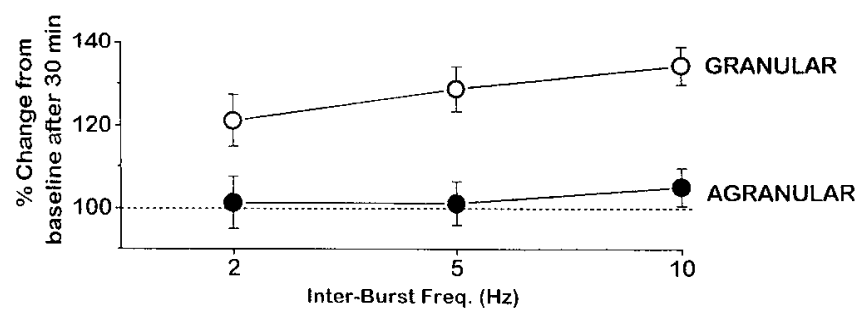

Figure 3. Frequency dependence of LTP induction in the granular and agranular areas, as measured from field potential responses. Inter-burst frequency during burst-sequence stimulation was varied, while all other features of the stimuli remained constant (i.e., one burst $=5$ pulses at $100 \mathrm{~Hz}$; one burst sequence $=10$ bursts repeated at 2,5 , or $10 \mathrm{~Hz}$; six sequences repeated at $0.1 \mathrm{~Hz}$ ). $A$, Results of three experiments each from granular (open symbols) and agranular (solid symbols) areas, as frequency of burst-sequences $(B S)$ was varied from $10 \mathrm{~Hz}$ to $2 \mathrm{~Hz}$. Note consistent LTP in granular area but not in the agranular area. $B$, Summary of results. Data are expressed as the percentage of change in slope measured $30 \mathrm{~min}$ after burst stimulation; each point is the mean 1 SEM for four or five experiments.

Numerous reports show that the induction of LTP can be facilitated by suppressing $\mathrm{GABA}_{\mathrm{A}}$ receptor-mediated inhibition with a drug such as BMI (e.g., Wigström and Gustafsson, 1983; Kanter and Haberly, 1992). In order to avoid the epileptiform activity that follows even very low doses of BMI in neocortex (Chagnac-Amitai and Connors, 1989), we used a method previously described for visual cortex (Bear et al., 1992); BMI was applied to a very limited area by placing it into the recording pipette and allowing it to leak out slowly but continuously. As shown previously (Bear et al., 1992), the field potentials recorded with BMI-filled pipettes were somewhat larger and longer-lasting than those recorded with control pipettes. With BMI present, theta-burst stimulation of the middle layers of the agranular cortex consistently generated LTP (Fig. 4, open circles). A similar form of ITP was also observed in granular cortex using BMIfilled recording pipettes (not shown).

The potentiation observed in agranular cortex, with BMI, differed from LTP in granular cortex, without BMI, in two ways.
First, agranular LTP displayed a relatively slow onset, rising over the first $10 \mathrm{~min}$ to its sustained level of $30-55 \%$ above control after $60 \mathrm{~min}$. Second, agranular LTP in the S1 (conditioned) pathway was accompanied by a long-lasting depression of the $\mathrm{S} 2$ (unconditioned) pathway (Fig. $4 A$, solid circles). This heterosynaptic LTD was not observed in the agranular cortex under control recording conditions, that is, in the absence of BMI (Fig. $4 A$, triangles).

\section{LTD occurs in both granular and agranular cortex}

Low-frequency stimulation of the $\mathrm{S} 1$ (vertical) pathway $(1 \mathrm{~Hz}$ for $15 \mathrm{~min}$ ) was followed by a stable decrease of layer II/III responses in both granular and agranular cortex. Figure 5 illustrates averaged results from granular cortex and agranular cortex. Depression was maximal immediately after cessation of the conditioning tetanus, and responses then increased gradually over the next $10 \mathrm{~min}$ before stabilizing at their final level. The time coursc and magnitude (about $25 \%$ decrease after $50 \mathrm{~min}$ ) of depression were indistinguishable in the two areas. LTD was also input specific in both areas; the unconditioned S2 pathway was unchanged after tetanizing the S1 pathway.

\section{Effects of NMDA receptor antagonists and nifedipine on the induction of LTP in the granular cortex and STP in agranular cortex}

Both STP and LTP in the CA1 region of the hippocampus (Malenka and Nicoll, 1994), and LTP in the visual cortex (Kirkwood and Bear, 1994a; however, see Komatsu et al., 1991), can be prevented by application of an NMDA receptor antagonist during the induction period. When AP5 was applied to untetanized slices of granular and agranular cortex, it depressed the later phase of the field potential response to single stimuli (Fig. $6 B$; cf. Bear et al., 1992). In the presence of AP5, $5 \mathrm{~Hz}$ theta-burst stimulation did not induce LTP in granular cortex (Fig. 6A, open circles). Instead, responses were depressed for several min before returning to baseline values. As a control, all slices of granular cortex tested with an AP5-filled electrode were subsequently tested with an electrode filled with $\mathrm{NaCl}$ alone; in every case, LTP was then evoked with the standard $5 \mathrm{~Hz}$ theta-burst stimulation. Theta-burst stimulation of the agranular cortex in the presence of AP5 had essentially no effect (Fig. 6A, solid circles); the STP seen in agranular cortex under control conditions (Fig. $2 A, B$ ) was absent. Thus, LTP in the granular area, and STP in both areas, are abolished by the NMDA antagonist AP5.

In the hippocampus, blockade of voltage-dependent calcium channels does not interfere with the induction of LTP, but does seem to block a nonassociative, transient form of potentiation (Kullman et al., 1992). In the visual neocortex, however, some recent reports (Komatsu and Iwakiri, 1992; Aroniadou et al., 1993) claim that antagonists of voltage-sensitive calcium channels may interfere with some forms of LTP. Figure $7 A$ shows the effects of theta-burst stimulation in the presence of nifedipine, a blocker of L-type voltage-sensitive calcium channels. LTP was still reliably induced in the granular cortex in the presence of nifedipine. When compared to control LTP (Fig. 2), however, LTP induced in the presence of nifedipine tended to increase more slowly after the conditioning tetanus, and its final magnitude was lower (Fig. 7A, open circles). Nevertheless, LTP was consistently and reliably induced in every granular slice tested. In the agranular cortex, delivery of theta-burst stimulation in the presence of nifedipine yielded an STP very similar to control responses (Fig. 7A, solid circles). 
Figure 4. LTP induction in agranular arca following disinhibition. Ficld potential recordings were made with BMI-filled micropipettes; stimulation and recording arrangements were the same as shown in Figures 1 and 2. A, Theta-burst stimulation induced LTP in the conditioned input (Sl; open circles), while producing heterosynaptic LTD in the nonconditioned input (solid circles, $S 2$; horizontal pathway). In a separate series of experiments, LTD was not generated in the horizontal S2 pathway after theta-burst stimulation of the vertical S1 pathway in the absence of BMI (triangles). Each symbol sct is derived from seven experiments. $B, \mathbf{E x}$ amples of field potentials recorded with BMI-filled micropipettes in agranular cortex, from experiments in $A$. Illustrated responses were obtained before and 30 min after (arrows) application of theta-burst stimulation to the vertical pathway (SI) only.
A

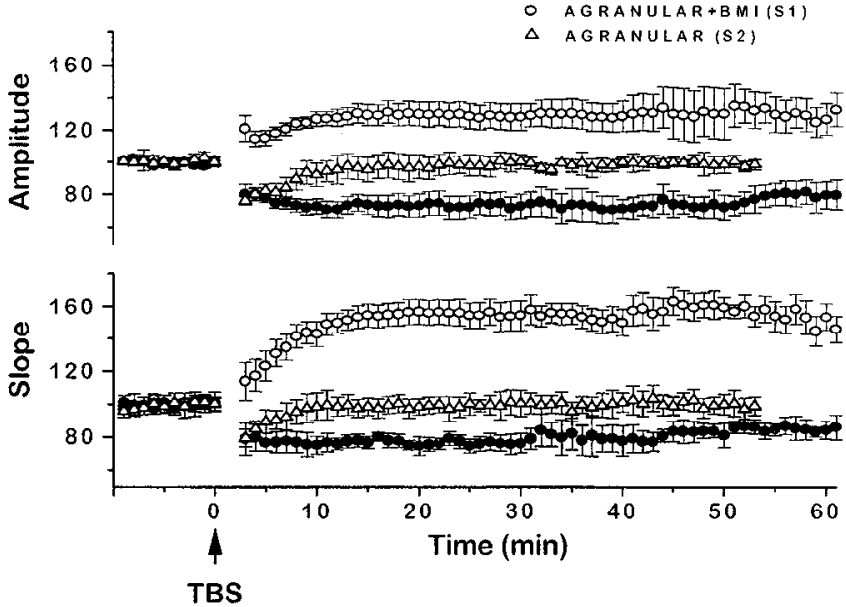

B AGRANULAR+BMI
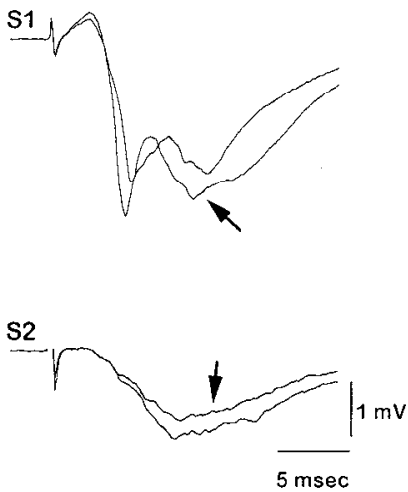

To assure ourselves that nifedipine was indeed acting on local synaptic circuits under our expcrimental conditions, we examined its effect on the evoked field potentials from single sites across a range of stimulus intensities. Field potentials were significantly slowed and depressed by nifedipine (Fig. $7 B$ ). Graphs of stimulus intensity vs. response amplitude (Fig. $7 C$ ) show that nifedipine increased the threshold for a measurable response, and depressed the maximal size of the response.

\section{Effects of NMDA receptor antagonists and nifedipine on the induction of LTD in granular and agranular cortex}

LTD induced by low-frequency stimulation has been reported to depend on NMDA receptors both in the hippocampus (Mulkey and Malenka, 1992; Dudek and Bear, 1993) and in the visual cortex (Kirkwood and Bear, 1994b). However, recent evidence challenges this consensus for LTD in the hippocampus, claiming that it is not NMDA receptor-dependent, but is prevented by blockers of L-type voltage-sensitive calcium channels (Bolshakov and Siegelbaum, 1994). We tested the sensitivity of LTD to antagonists of NMDA receptors and L-type channels in the granular and agranular cortices.

Figure 8 shows that AP5 completely abolished LTD in both cortical areas. Interestingly, however, in the presence of AP5 the conditioning stimuli led to a transient depression, which slowly decayed over 10-15 min before returning to baseline. The time course and amplitude of this short-term depression was similar in granular and agranular areas.

Figure 9 illustrates the effects of nifedipine on the responses to low-frequency stimulation in granular and agranular arcas. Clear LTD was observed in both areas. The most obvious effect of nifedipine was the absence of the transient phase of shortterm depression, which is normally apparent under control conditions (Fig. 5A) and is particularly pronounced following stimulation in the presence of AP5 (Fig. 8). The magnitude of LTD in both areas was also slightly smaller with nifedipine compared to control slices.

Table 1 summarizes the pooled results of theta-burst and lowfrequency stimulation, and drug manipulations, on long-term alterations in synaptic strength in granular and agranular cortex.
Synaptic facilitation occurs during theta-burst stimulation of granular cortex but not agranular cortex

A striking result from this study is that theta-burst stimulation reliably induced LTP in the granular cortex, but not in the agranular cortex. Neither the strength of the conditioning pathways, nor burst-frequency-sensitivity seem to account for this difference; indeed, when inhibition is suppressed, agranular cortex readily generates LTP. Studies of LTP induction in the CA1 region of hippocampus have stressed the need for strong depolarization of the postsynaptic cell during the induction process (Bliss and Collingridge, 1993). This facilitates the gating of NMDA receptor-coupled channels, and the consequent entry of $\mathrm{Ca}^{2+}$ into the neuron. We reasoned that short-term synaptic changes during the theta-burst induction sequence might differ in the two cortical areas, and that this might account for their unequal proclivity to generate LTP.

Intracellular recordings during theta-burst sequences show that EPSPs in the granular cortex are dramatically facilitated, while those of agranular cortex remain quite stable (Fig. 10A). Facilitation in granular area neurons occurs both within a burst sequence, and across sequences (compare the size and duration of burst-induced EPSPs in sequences 1, 3, and 6 in Fig. 10A, left panels). Within a sequence, EPSPs grow progressively in amplitude, and also ride upon a gradually depolarizing baseline nnembrane potential. As an index of synaptic effectiveness duiing theta-burst stimulation we measured the area of the burstinduced postsynaptic potential, minus the baseline potential, and calculated a mean for the five responses comprising each burst. This gives a measure of the effectiveness of each burst within a sequence. As shown in Figure $10 B$, burst responses of granular cortex (open symbols) increased during the progression of thetaburst sequences, reaching a plateau after about four sequences. In stark contrast, responses from the agranular cortex (solid symbols) changed little between sequences one and six.

\section{Discussion}

Eclectic forms of synaptic plasticity expressed in granular and agranular areas

Our experiments revealed several forms of synaptic plasticity in two areas of neocortex studied, and these are summarized in 
A

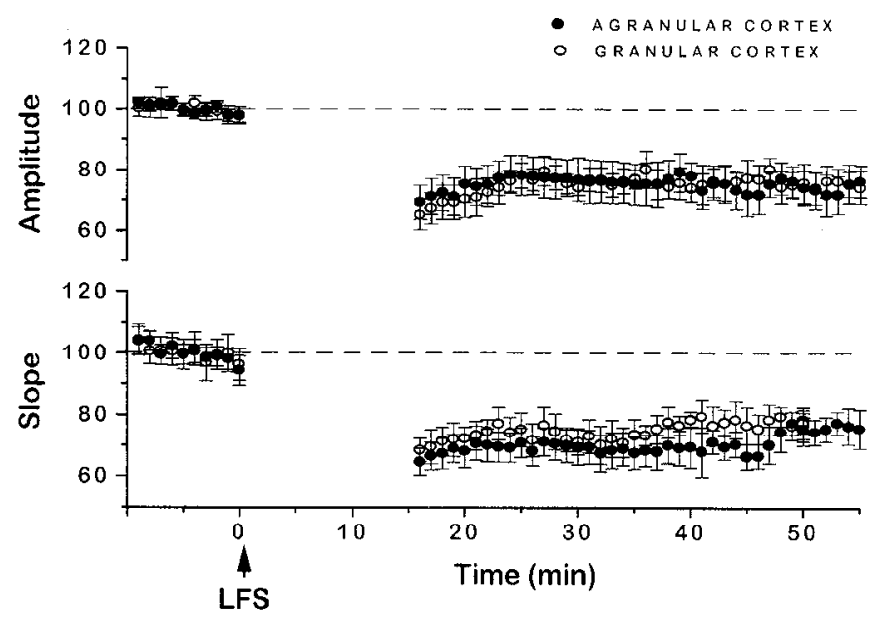

Table 1. Most resemble forms of plasticity described previously in various regions of cerebral cortex, especially hippocampus, but there is cnough ambiguity and disagreement in the literature that it is worth clarifying our terminology as we summarize our findings.

LTP is a sustained (more than $30 \mathrm{~min}$ ) increase in synaptic responsiveness that follows conditioning stimuli. A principal result of this study was that vertical pathways of the granular somatosensory area easily expressed LTP, while those of the agranular motor area did not. Agranular cortex did generate LTP if $\mathrm{GABA}_{\mathrm{A}}$ receptors were partially blocked, so it clearly has the necessary molecular machinery for long-term synaptic enhancement. STP is a synaptic enhancement that lasts only about 5-20

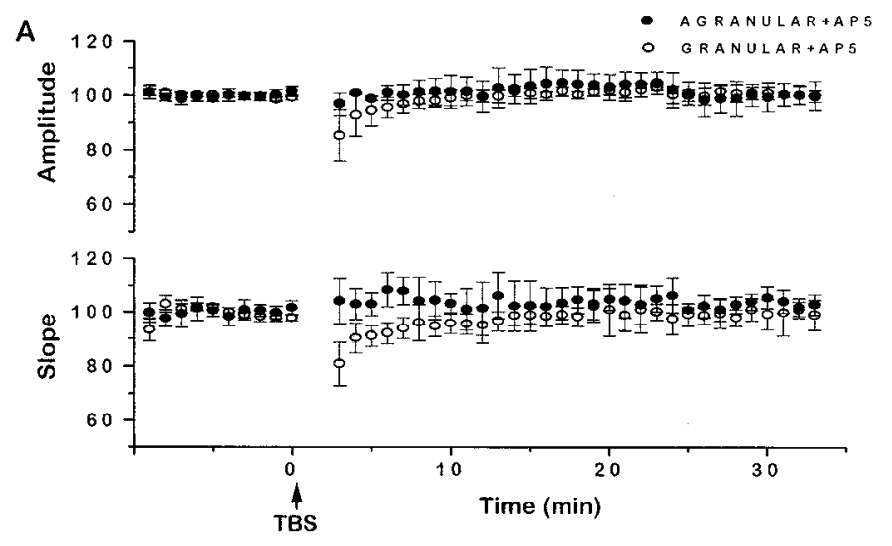

B

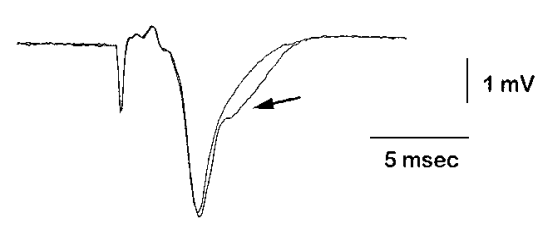

Figure 6. Effects of theta-burst stimulation on granular and agranular areas in the presence of the NMDA-receptor antagonist (AP5). A, AP5 prevented the induction of LTP and STP in the granular (five experiments) and agranular (three experiments) areas, respectively (compare with results under control conditions, in Fig. 2). B, Application of AP5 in the bathing medium blocked a small, late component of the field potential in both granular and the agranular cortex. Illustrated is an example of a response from the agranular area before (arrow) and after the application of AP5 $(100 \mu \mathrm{M})$.

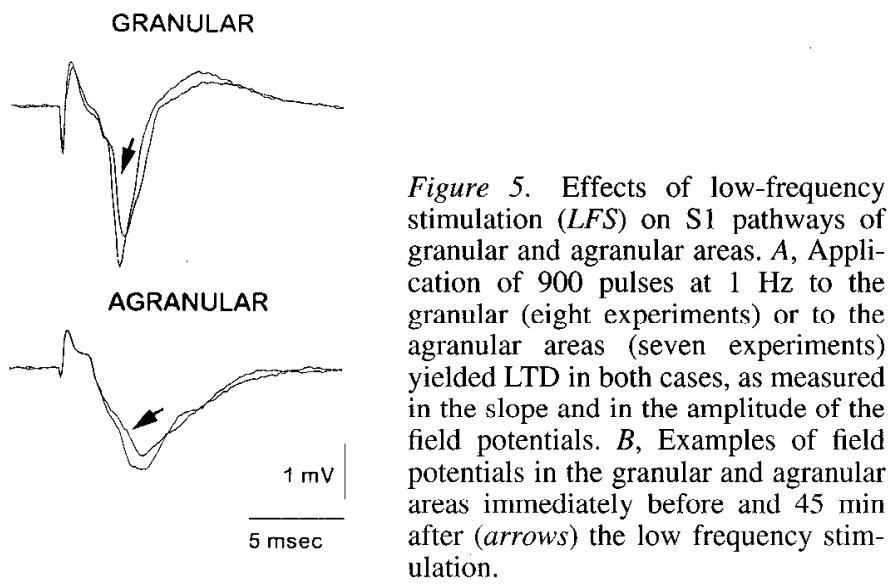

min, and it has been studied extensively in the CAl region of hippocampus (Malenka, 1991; Malenka and Nicoll, 1993), but little or not at all in neocortex. In our study, the agranular cortex generated STP following theta-burst stimulation under control conditions. It seems likely that the granular cortex also generates STP, although its decaying phase is often obscured by the LTP; responses were transiently elevated following the conditioning period, then began decaying with a time course similar to the STP of the agranular area (Fig. $2 A, B$ ). In addition, we have observed isolated STP in granular cortex when only a single theta-burst sequence was applied (Castro-Alamancos and Connors, unpublished observations). Interesting forms of brief synaptic enhancement occur during the theta-burst stimulation itself, in granular but not in agranular cortex (Fig. 10). This facilitation resembles other forms of transient enhancement seen in many synapses (Zucker, 1989).

LTD is a sustained ( $30 \mathrm{~min}$ or more) decrease in synaptic responsiveness following conditioning. In our study both granular and agranular areas generated reliable, and identical, LTD (Table 2). Under control conditions depression was maximal at the termination of the conditioning train, and then it decayed slightly over about $15 \mathrm{~min}$ to the sustained levels (Fig. 5A). Because this transient phase of depression resembles an inverse form of STP, it has been called STD by some (Artola and Singer, 1993). STD is revealed clearly when LTD is blocked with AP5 (Fig. 8), and it appeared to be largely absent in the presence of nifedipine (Fig. 9).

We conclude that neocortex has a rich array of mechanisms available to modify the effectiveness of its synapses. The differences between granular and agranular areas suggest that all regions may not share the same propensities for modifications of certain types.

\section{Mechanisms of synaptic plasticity in sensorimotor neocortex}

Analyses of synaptic plasticity often recognize two distinct mechanistic processes: induction and expression. Our results do not address the mechanisms of expression for any of the phenomena we observed. However, the fact that LTP, STP, and LTD were blocked by AP5 implies that all depend upon the activation of NMDA receptors during their induction phase. T'hese results are similar to those from the CA1 region of hippocampus (revicwed by Malenka and Nicoll, 1993), and are consistent with some studies of primary visual cortex (e.g., Artola and Singer, 


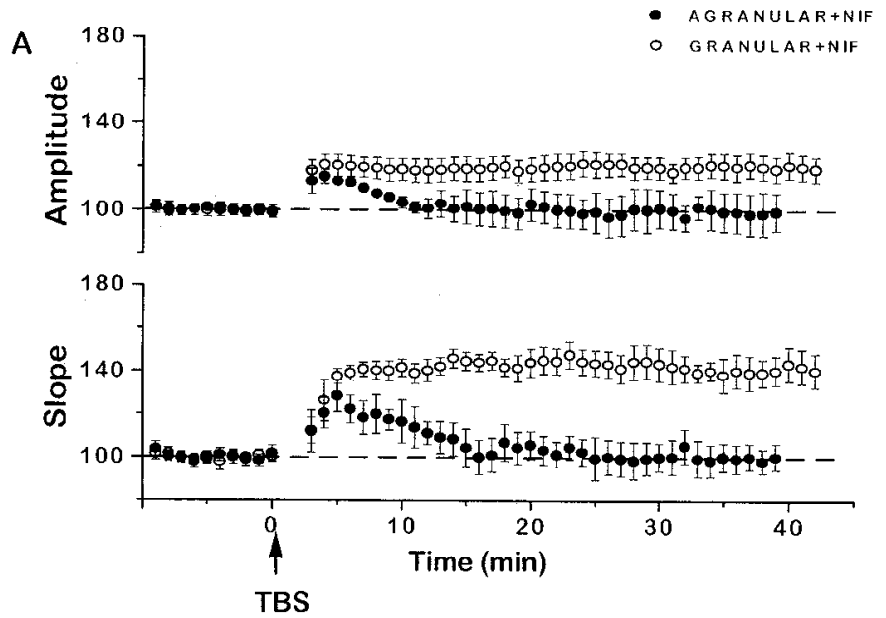

B
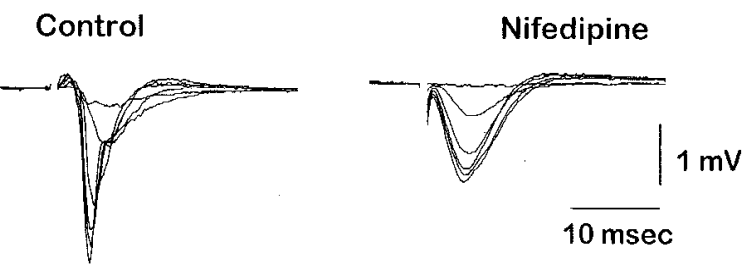

C

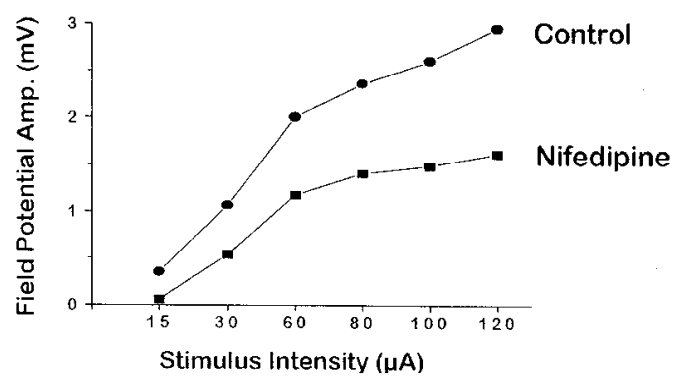

Figure 7. Effects of theta-burst stimulation on granular and agranular areas in the presence of the calcium channel blocker nifedipine. In all cases, nifedipine was included in the recording micropipette. $A$, Nifedipine did not block the induction of LTP in the granular area $(10$ experiments) or the induction of STP in the agranular area (4 experiments). $B$, Effect of nifedipine on field potentials in nontetanized slices. Field potentials were recorded at a range of stimulus intensities, first with control (saline) electrodes, then from the same site with nifedipinefilled electrodes. Similar effects of nifedipine were observed in both areas. $C$, Ficld potential amplitude as a function of stimulus current. Nifedipine increased the threshold of responses, and depressed their amplitude at all tested intensities.

1987; Kimura et al., 1989; Aroniadou and Teyler, 1991; Sah and Nicoll, 1991; Bear et al., 1992) but not others. Several studies have found LTP in visual cortex to be insensitive to NMDA receptor antagonists (e.g. Komatsu et al., 1991; Aroniadou et al., 1993), but these involved stimulation protocols quite different from those employed here $(2 \mathrm{~Hz}$ for $60 \mathrm{~min}$ in the case of $\mathrm{Ko}$ matsu et al., 1991). When theta-burst stimulation was used to induce LTP (Kirkwood et al., 1993), and low-frequency stimulation was used to induce LTD (Kirkwood and Bear, 1994b) in visual cortex, as in our own experiments, both phenomena were abolished by AP5. The presumed link between NMDA receptors and the induction of STP, LTP, or LTD is an influx of $\mathrm{Ca}^{2+}$ through NMDA-gated channels (Debanne and Thompson, 1994). Presumably the magnitude, time course, and location of intracellular $\mathrm{Ca}^{2+}$ elcvations determine, in part at lcast, which forms of plasticity ensue.

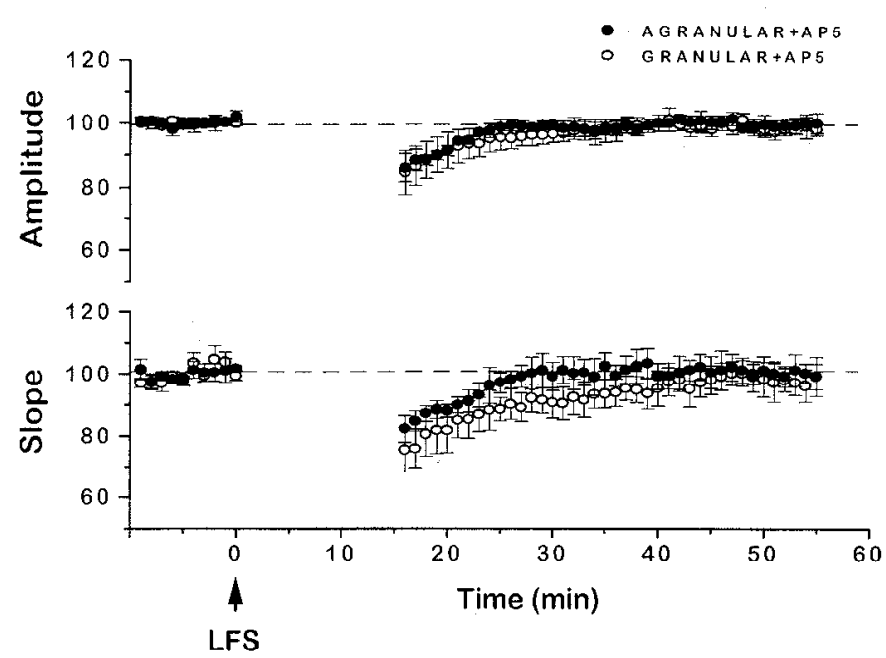

Figure 8. Effect of low-frequency stimulation (LFS) in granular and agranular areas in the presence of the NMDA-receptor antagonist (AP5). AP5 prevented the induction of LTD in both areas (compare with control results in Fig. 5). Low-frequency stimulation did yield an STD in both areas in the presence of AP5. Data are based on field potential recordings from eight experiments from each area.

Interestingly, we found that STD was not blocked by the NMDA receptor antagonist AP5. This is also consistent with previous observations in hippocampus (Mulkey and Malenka, 1992; Dudek and Bear, 1993) and visual cortex (Bröcher et al., 1992; Kirkwood and Bear, 1994b), and implies that the induction of LTD and STD are fundamentally different. The mechanisms of STD have not been closely examined in any system, however.

In addition to NMDA-gated channels, $\mathrm{Ca}^{2+}$ can enter cells via voltage-gated channels. Indeed, $\mathrm{Ca}^{2+}$ entry through T-type (low threshold) channels has been implicated in the induction process of low-frequency stimulation-generated ITP in kitten visual cortex (Komatsu et al., 1992). A recent report suggests that LTD in the hippocampus of young animals is induced by $\mathrm{Ca}^{2+}$ entry through L-type (high threshold) calcium channels, and not by

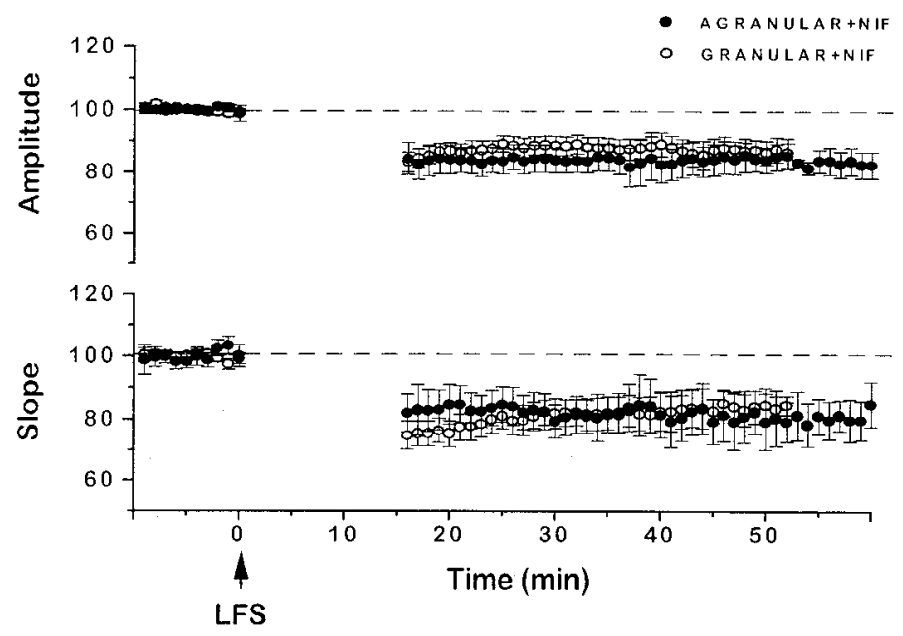

Figure 9. Effect of low-frequency stimulation (LFS) in granular and agranular areas in the presence of the calcium channel blocker nifedipine. LTD was generated in both areas, although the initial phase of STD observed under control conditions (see Fig. 5) was absent. Data are based on field potential recordings from 12 experiments from each area. 
Table 1. Comparison of long-term, activity-dependent changes of synaptic strength under different experimental conditions

\begin{tabular}{|c|c|c|c|c|}
\hline \multirow[b]{2}{*}{ Conditions } & \multicolumn{2}{|c|}{ Granular area } & \multicolumn{2}{|c|}{ Agranular area } \\
\hline & $\begin{array}{l}\% \text { of } \\
\text { baseline } \\
\text { (mean } \\
\pm \text { SEM) }\end{array}$ & $n$ & $\begin{array}{l}\% \text { of } \\
\text { baseline } \\
\text { (mean } \\
\pm \text { SEM) }\end{array}$ & $n$ \\
\hline 'Iheta-burst stimulation & $140 \pm 5^{*}$ & 10 & $107 \pm 5$ & 10 \\
\hline Theta-burst + BMI & & & $153 \pm 6^{*}$ & 7 \\
\hline Theta-burst + AP5 & $101 \pm 3$ & 5 & $102 \pm 3$ & 3 \\
\hline Theta-burst + nifedipine & $141 \pm 4^{*}$ & 10 & $105 \pm 8$ & 4 \\
\hline Low-frequency stimulation & $78 \pm 5^{*}$ & 8 & $70 \pm 6^{*}$ & 7 \\
\hline Low-frequency + AP5 & $100 \pm 3$ & 8 & $102 \pm 4$ & 8 \\
\hline Low-frequency + nifedipine & $83 \pm 4^{*}$ & 12 & $79 \pm 9^{*}$ & 12 \\
\hline
\end{tabular}

Tabulated data are the sizes of the maximal slope responses $30 \mathrm{~min}$ after the end of conditioning stimulation, expressed as a percentage of the preconditioning baseline level.

* Significantly different from baseline level $(p<0.01)$, two-tailed $t$ test.
NMDA receptors (Bolshakov and Siegelbaum, 1994). We found that nifedepine, an L-type $\mathrm{Ca}^{2+}$ channel blocker, did not eliminate LTP in granular cortex, STP in agranular cortex, or LTD in either area. Nifedepine was not without effect; it did slightly depress the magnitude of LTP and LTD, and it appeared to depress or eliminate the STD phase of depression (Fig. 9), and slow the onset of LTP in granular cortex (Fig. 7). Therefore, it may be that L-type voltage-sensitive calcium channels contribute to the induction of neocortical LTP and STP, but they are not essential.

Robust synaptic facilitation during theta-burst stimulation was observed in granular, but not agranular, cortex. Since LTP depends upon relatively strong activation of NMDA receptors (Malenka and Nicoll, 1993), it may be that synaptic facilitation during the induction phase is essential for the reliable expression of LTP. The larger, longer membrane depolarization that occurs during facilitation would strongly promote the opening of NMDA receptor-gated channels, and consequently the entry of LTP-inducing levels of intracellular $\mathrm{Ca}^{2+}$. The presence of both facilitation and LTP in granular cortex, and the absence of both in agranular cortex, strongly support this hypothesis. Theta-burst stimulation of agranular cortex, which is not accompanied by
1
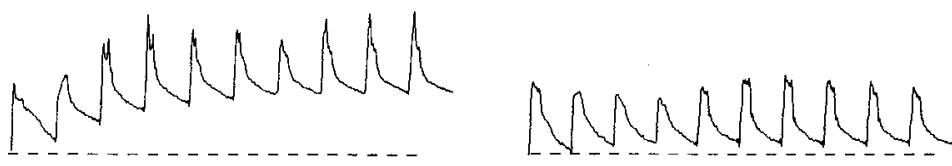

3
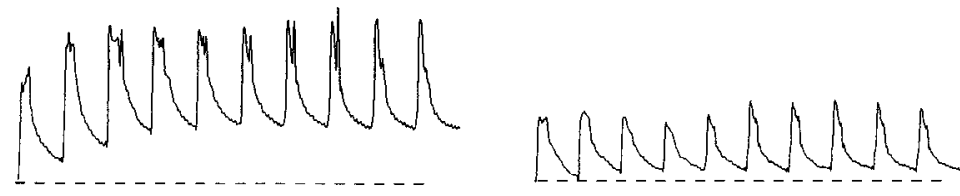

6

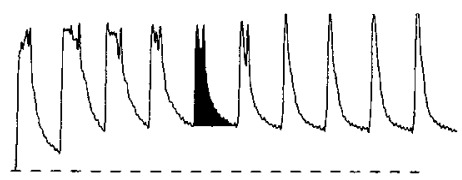

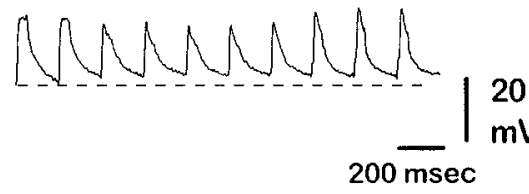

B

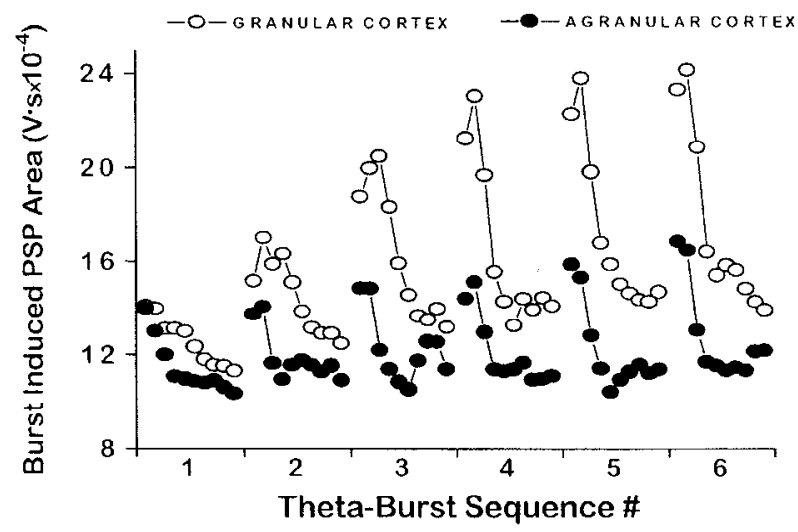

Figure 10. Comparison of neuronal membrane potential changes during theta-burst stimulation in the granular and agranular areas. A, Examples of intracellular recordings from pyramidal cells in the granular area (left) and the agranular area (right), showing responses to the first, third, and sixth theta-burst sequences, each sequence consisting of 10 bursts. Recordings have been filtered to reduce action potentials, for clarity. Note that the response of the cell from the granular area progressively increased from burst-toburst within the first sequence, and across sequences (compare the first and subsequent bursts from sequence 1 with those from sequences 3 and 6). Note also the gradual depolarization underlying individual burst responses. In contrast, responses from the cell in the agranular area remained relatively stable within and across sequences. $B$, Graphical comparison of synaptic responses during theta-burst stimulation. Data are the mean of 10 neurons from each cortical area, stimulated as in $A$. Each circle represents the area of a burst-induced postsynaptic potential, measured as indicated in burst 5 of sequence 6 in $A$ (filled area). Thus, this area measure does not take into account shifts of the baseline level of membrane potential. Areas were calculated using Simpson's rule with the aid of EXPERIMENTER'S WORKBENCH, and are expressed as $V \cdot$ sec. Variances are not illustrated, but the mean SEM for each point was $1.5 \times 10^{-4} \mathrm{~V} \cdot \mathrm{sec}$. Facilitation across sequences was prominent in the granular area, but not in the agranular area. 


\begin{tabular}{lll}
\hline $\begin{array}{l}\text { Table 2. Forms of synaptic plasticity observed in granular and } \\
\text { agranular neocortex }\end{array}$ & Granular area & Agranular area \\
\hline $\begin{array}{ll}\text { Long-term potentiation } \\
\text { (normal conditions) }\end{array}$ & + & - \\
Long-term potentiation & & \\
$\quad$ during disinhibition) & + & + \\
Short-term potentiation & + & - \\
Facilitation & & - \\
$\quad$ during theta-burst) & + & + \\
Long-term depression & + & + \\
Short-term depression & + &
\end{tabular}

"+" indicates that a cortical area demonstrated that particular form of plasticity in this study, and "-." indicates that the form was not observed.

facilitation, generated only STP. In the hippocampus, STP is thought to be associated with more moderate increases of intracellular $\mathrm{Ca}^{2+}$ (Hanse and Gustafsson, 1992; Malenka et al., 1992). Revealing the mechanisms underlying facilitation in granular cortex, and the reasons for its absence in agranular cortex, will be important for understanding LTP induction in these two areas. There are many potential explanations for the difference between areas, including the intrinsic release properties of presynaptic terminals, some aspect of neurons or circuits affecting the strength or pattern of inhibition, or the properties of postsynaptic NMDA receptor.

\section{Comparative plasticity of granular and agranular neocortex}

Neocortex is extensively subdivided into areas of anatomical and functional specialization (Creutzfeldt, 1993), but almost nothing is known about the specialization of cellular physiology across areas. The many modes of synaptic plasticity are a type of specialization. Several literature reviews have explicitly compared plasticity in hippocampus with that of neocortex (Bindman et al., 1991; Artola and Singer, 1993; Bear and Malenka, 1994; Debanne and Thompson, 1994). Hippocampus and visual cortex are about as diverse as cerebral cortical regions can be, but still it is not clear precisely how (or if) their mechanisms of plasticity differ. It may be relevant that very few experimental studies have actually compared the two structures under identical laboratory conditions (however, see Kirkwood et al., 1993). Here we have shown, in the same in vitro slices, that the expression of some forms of synaptic plasticity can be quite different in two related but distinct areas of neocortex.

The relevance of synaptic plasticity to processes such as learning, development, and neural injury is widely assumed, but in fact there is currently very little evidence supporting this link for any area of brain. In this context, it may help to summarize the properties of the two areas we have studied. The granular and agranular areas of the rat frontoparietal cortex represent two functionally distinct regions (Donoghue and Wise, 1982). The granular area lies lateral and posterior to the agranular area, and is named for the small, dense neurons of its layer IV. The agranular cortex lacks a dense layer IV; it also has a relatively thick layer V. Granular cortex, and its interspersed "dysgranular" inclusions and granular "barrels," receives topographically organized inputs from the ventral posterior medial and ventral posterior lateral thalamic nuclei (Jones and Diamond, 1994). Neurons in this area can be activated by light cutaneous and vibrissa stimulation. By anatomical and physiological criteria, granular cortex is the primary somatosensory area in the rodent. The agranular area receives its primary ascending input from the ventral lateral nucleus of the thalamus. Its cells are not easily activated by somatosensory input, but when stimulated with low intensity in its deep layers, agranular cortex elicits movements of specific body parts; thus, agranular cortex corresponds to the primary motor area in rodents (Donoghue and Wise, 1982). There is also a granular region where the motor and somatosensory functions for the hindlimb overlap.

Studies of mature, intact animals indicate that both the granular (Wall and Cusick, 1984; Diamond et al., 1993) and agranular (Donoghue et al., 1990; Castro-Alamancos et al., 1992) areas of neocortex are subject to extensive modification of their functional organization following peripheral or central manipulations. The mechanisms underlying these modifications are largely unknown. However, there are several reasons to think that activity-dependent synaptic plasticity may play a role. First, plasticity in vivo can occur quite rapidly. Studies have documented changes within minutes to hours (Recanzone et al., 1990; Kaas, 1991; Calford and Tweedale, 1988; Donoghue et al., 1990; Gilbert, and Wiesel, 1992). In vitro induction protocols can establish synaptic modification within seconds to minutes. Second, reorganizations can be quite specific, suggesting that synaptic modifications must be specific. Indeed, input specificity has been demonstrated for LTP and LTD in sensorimotor cortex. Third, studies in vivo suggest that synapses are both strengthened and weakened. In vitro results demonstrate that there are multiple mechanisms for both activity-dependent enhancement and depression of synapses.

The many areas of neocortex may have similar types of neurons, and they may share a basic pattern of neural circuitry (Douglas and Martin, 1991). However, they are obviously different in the details of their cell arrangements, their inputs and outputs, the distribution and densities of proteins expressed, and in their functions-this is how we distinguish areas, after all. Here we have demonstrated that areas may also differ in their ability to generate synaptic modifications. Further studies on different pathways and other areas will be necessary to estimate the extent of plasticity diversity. The two areas examined here, with strikingly different abilities to generate facilitation and LTP in their vertical pathways, will serve as a useful tool for probing the mechanisms of synaptic plasticity in neocortex.

\section{References}

Aroniadou VA, Teyler TJ (1991) The role of NMDA receptors in longterm potentiation (LTP) and depression (LTD) in rat visual cortex. Brain Res 562:136-143.

Aroniadou VA, Maillis A, Stefanis CC (1993) Dihydropyridine-sensitive calcium channels are involved in the induction of $N$-methyl-Daspartate receptor independent long-term potentiation in visual cortex in adult rats. Neurosci Lett 151:77-80.

Artola A, Singer W (1987) Long-term potentiation and NMDA receptors in visual cortex. Nature 330:649-652.

Artola A, Singer W (1993) Long-term depression of excitatory synaptic transmission and its relationship to long-term potentiation. Trends Neurosci 16:480-487.

Baranyi A, Szente MB (1987) Long-lasting potentiation of synaptic transmission requires postsynaptic modifications in the neocortex. Brain Res 423:378-384.

Baranyi A, Szente MB, Woody CD (1991) Properties of associative long-lasting potentiation induced by cellular conditioning in the motor cortex of conscious cats. Neuroscience 42:321-334.

Bear MF, Kirkwood A (1993) Neocortical long-term potentiation. Curr Opin Neurobiol 3:197-202.

Bear MF, Malenka RC (1994) Synaptic plasticity: LTP and LTD. Curr Opin Neurobiol 4:389-399. 
Bear MF, Press WA, Connors BW (1992) Long-term potentiation in slices of kitten visual cortex and the effects of NMDA receptor blockade. J Neurophysiol 67:841-851.

Bindman LJ, Murphy KPSJ, Pockett S (1988) Postsynaptic control of the induction of long-term changes in efficacy of transmission at neocortical synapses in slices of rat brain. J Neurophysiol 60:1053-1065.

Bindman LJ, Chirstofi G, Murphy K, Nowicki A (1991) Long-term potentiation and long-term depression in the neocortex and hippocampus: an overview. In: Aspects of synaptic transmission (Stone TW, ed), p 3. London: Taylor Francis.

Bliss TVP, Collingridge GL (1993) A synaptic model of memory: longterm potentiation in the hippocampus. Nature 361:31-39.

Bolshakov VY, Siegelbaum SA (1994) Postsynaptic induction and presynaptic expression of hippocampal long-term depression. Science 264:1148-1152.

Braöcher S, Artola A, Singer W (1992) Intracellular injection of $\mathrm{Ca}^{2+}$ chelators blocks induction of long-term depression in rat visual cortex. Proc Natl Acad Sci USA 9:123-127.

Calford MB, Tweedale R (1988) Immediate and chronic changes in responses of somatosensory cortex in adult flying fox after digit amputation. Nature 332:446-448.

Castro-Alamancos MA, Garcia-Segura LM, Borrell J (1992) Transfer of function to a specific area of the cortex after induced recovery from brain damage. Eur J Neurosci 4:853-863.

Chagnac-Amitai Y, Connors BW (1989) Horizontal spread of synchronized activity in neocortex, and its control by GABA-mediated inhibition. J Neurophysiol 61:747-758.

Connors BW, Gutnick MJ (1990) Intrinsic firing patterns of diverse neocortical neurons. Trends Neurosci 13:99-104.

Connors BW, Malenka RC, Silva LR (1988) Two inhibitory postsynaptic potentials, and $\mathrm{GABA}_{\wedge}$ and $\mathrm{GABA}_{\mathrm{B}}$ receptor-mediated responses in neocortex of rat and cat. J Physiol (Lond) 406:443-468.

Creutzfeldt OD (1993) Cortex cerebri: performance, structural and functional organization of the cortex. Göttingen: Mary Creutzfeldt.

Debanne D, Thompson SM (1994) Calcium: trigger for long-term depression and potentiation in the hippocampus. News Physiol Sci 9: 256-260.

Dempsey EW, Morison RS (1943) The electrical activity of a thalamocortical relay systcm. Am J Physiol 138:283-296.

Diamond ME, Armstrong-James M, Ebner FE (1993) Experience-dependent plasticity in adult rat barrel cortex. Proc Natl Acad Sci USA 90:2082-2086.

Donoghue JP, Wise S (1982) The motor cortex of the rat: cytoarchitecture and microstimulation mapping. J Comp Neurol 212:76-88.

Donoghue JP, Suner S, Sanes JN (1990) Dynamic organization of primary motor cortex output to target muscles in adult rats. II. Rapid reorganization following motor nerve lesions. Exp Brain Res 79:492503.

Douglas RJ, Martin KAC (1991) A functional microcircuit for cat visual cortex. J Physiol (Lond) 440:735-769.

Dudek SM, Bear MF (1992) Homosynaptic long-term depression in area CAl of hippocampus and the effects of NMDA receptor blockade. Proc Natl Acad Sci USA 89:4363-4367.

Dudek SM, Bear MF (1993) Bidirectional long-term modification of synaptic effectiveness in the adult and immature hippocampus. J Neurosci 13:2910-2918.

Gilbert CD, Wiesel TN (1992) Receptive field dynamics in adult primary visual cortex. Nature $356: 150-152$.

Hanse E, Gustafsson B (1992) Postsynaptic, but not presynaptic activity controls the early time course of long-term potentiation in the dentate gyrus. J Neurosci 12:3226-3240.

Hess G, Donoghue JP (1994) Long-term potentiation of horizontal connections provides a mechanism to reorganize cortical motor maps. J Neurophysiol 71:2543-2547.

Hirsch JA, Gilbert CD (1993) Long-term changes in synaptic strength along specific intrinsic pathways in the cat visual cortex. J Physiol (Lond) 461:247-262.

Iriki A, Pavlides C, Keller A, Asanuma H (1991) Long-term potentiation in the motor cortex. Science 245:1385-1387.

Jacobs KM, Donoghue JP (1991) Reshaping the cortical motor map by unmasking latent intracortical connections. Science 251:944-947.
Jones EG, Diamond IT, eds (1994) Cerebral cortex, Vol 11, The barrel cortex of rodents, in press. New York: Plenum.

Kaas JH (1991) Plasticity of sensory and motor maps in adult animals. Annu Rev Neurosci 14:137-168.

Kanter ED, Haberly LB (1993) Associative long-term potentiation in piriform cortex slices requires GABA $_{A}$ blockade. J Neurosci 13 $2477-2482$.

Kimura F, Nishigori A, Shirokawa T, Tsumoto T (1989) Long-term potentiation and NMDA receptors in the visual cortex of young rats. J Physiol (Lond) 414:125-144.

Kirkwood A, Bear MF (1994a) Hebbian synapses in visual cortex. J Neurosci 14:1634-1645.

Kirkwood A, Bear MF (1994b) Homosynaptic long-term depression in the visual cortex. J Neurosci 14:3404-3412.

Kirkwood A, Dudek SM, Gold JT, Aizenman CD, Bear MF (1993) Common forms of synaptic plasticity in the hippocampus and neocortex in vitro. Science, 260:1518-1521.

Komatsu Y, Iwakiri M (1992) Low-threshold $\mathrm{Ca}^{2+}$ channels mediate induction of long-term potentiation in kitten visual cortex. J Neurophysiol 65:20-32.

Komatsu Y, Nakajima S, Toyama K (1991) Induction of long-term potentiation without the participation of $N$-methyl-D-aspartate receptors in the kitten cortex. J Neurophysiol 65:20-32

Kullman DM, Perkel DJ, Manabe T, Nicoll RA (1992) $\mathrm{Ca}^{2+}$ entry via postsynaptic voltage-sensitive $\mathrm{Ca}^{2+}$ channels can transiently potentiate excitatory synaptic transmission in the hippocampus. Neuron 9 $1175-1183$.

Lee KS (1982) Sustained enhancement of evoked potentials following brief, high-frequency stimulation of the cerebral cortex in vitro. Brain Res 239:617-623.

Lee SM, Weisskopf MG, Ebner FF (1991) Horizontal long-term potentiation of responses in rat somatosensory cortex. Brain Res 544 303-310.

Madison DV, Malenka RC, Nicoll RA (1991) Mechanisms underlying long-term potentiation of synaptic transmission. Ann Rev Neurosc 14:379-397.

Malenka RC (1991) Postsynaptic factors control the duration of synaptic enhancement in area CA1 of the hippocampus. Neuron 6:5360.

Malenka RC, Nicoll RA (1993) NMDA-receptor-dependent synaptic plasticity: multiple forms and mechanisms. Trends Neurosci 16:521527

Malenka RC, Lancaster B, Zucker RS (1992) Temporal limits on the rise in postsynaptic calcium required for the induction of long-term potentiation. Neuron 9:121-128.

Mulkey RM, Malenka RC (1992) Mechanisms underlying induction of homosynaptic long-term depression in the area CA1 of the hippocampus. Neuron 9:967-975.

Recanzone GH, Allard TT, Jenkias WM, Merzenich MM (1990) Receptive field changes induced by peripheral nerve stimulation in S of adult cats. J Neurophysiol 63:1213-1225.

Recanzone GII, Merzenich MM, Dinse HR (1992) Expansion of the cortical representation of a specific skin field in primary somatosensory cortex by intracortical microstimulation. Cereb Cortex 2:181196.

Sah P, Nicoll RA (1991) Mechanisms underlying potentiation of synaptic transmission in rat anterior cingulate cortex in vitro. J Physiol (Lond) 433:615-630.

Sutor B, Hablitz JJ (1989) Long-term potentiation in frontal cortex: role of NMDA-modulated polysynaptic excitatory pathways. Neurosci Lett 97:111-117.

Wall JT, Cusick CG (1984) Cutaneous responsiveness in primary somatosensory (S-I) hindpaw cortex before and after hindpaw deafferentation in adult rats. J Neurosci 4:1499-1515.

Wigstrom H, Gustafsson B (1983) Facilitated induction of hippocampal long-lasting potentiation during blockade of inhibition. Nature 301: 603-604

Williams S, Johnston D (1989) Long-term potentiation of hippocampal mossy fiber synapses is blocked by postsynaptic injection of calcium chelators. Neuron 3:583-588.

Zalutsky RA, Nicoll RA (1990) Comparison of two forms of long-term potentiation in single hippocampal neurons. Science 248:1619-1624

Zucker RS (1989) Short-term synaptic plasticity. Ann Rev Neurosci $12: 13-31$. 